\title{
ERRATUM
}

\section{A quantitative mean ergodic theorem for uniformly convex Banach spaces - ERRATUM}

\author{
U. KOHLENBACH and L. LEUŞTEAN
}

doi:10.1017/S0143385708001004, Published by Cambridge University Press,

17 March 2009.

During the editorial production of the paper [1], a typo in formula (5) of Theorem 2.1 occurred which must be corrected to $\Phi(\varepsilon, g, b, \eta):=M \cdot \tilde{h}^{K}(1)$.

\section{REFERENCE}

[1] U. Kohlenbach and L. Leuştean. A quantitative mean ergodic theorem for uniformly convex Banach spaces. Ergod. Th. \& Dynam. Sys. in press. 